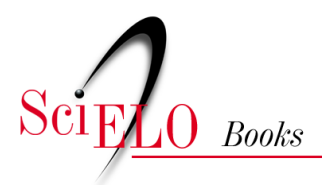

Parte II - Características e manifestações do modelo brasileiro: algumas reflexões

\title{
Desigualdade e pobreza no Brasil
}

\author{
Ana Carla França Ribas Zanini \\ Cleoci Werle Rockenbach
}

\section{SciELO Books / SciELO Livros / SciELO Libros}

ZANINI, A.C.F.R., and ROCKENBACH, C.W. Desigualdade e pobreza no Brasil. In: ROTTA, E., LOPES, H. C., and ROSSINI, N., eds. O modelo de desenvolvimento brasileiro das primeiras décadas do século XXI: aportes para o debate [online]. Chapecó: Editora UFFS, 2018, pp. 255-271. ISBN: 978-8564905-82-5. https://doi.org/10.7476/9788564905832.0012.

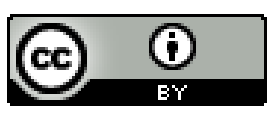

All the contents of this work, except where otherwise noted, is licensed under a Creative Commons Attribution 4.0 International license.

Todo o conteúdo deste trabalho, exceto quando houver ressalva, é publicado sob a licença Creative Commons Atribição 4.0.

Todo el contenido de esta obra, excepto donde se indique lo contrario, está bajo licencia de la licencia Creative Commons Reconocimento 4.0. 


\section{DESIGUALDADE E POBREZA NO BRASIL}

Ana Carla França Ribas Zanini

Cleoci Werle Rockenbach

\section{INTRODUÇÃO}

O presente capítulo tem como ponto de partida a análise de Cláudio Salvador Dedecca sobre o tema Redução da Desigualdade e Seus Desafios, um dos capítulos do livro Presente e Futuro do Desenvolvimento Brasileiro, publicado pelo Instituto de Pesquisa Econômica Aplicada (IPEA) em 2014.

A explanação de Dedecca (2014) explora a redução da desigualdade de renda das famílias brasileiras ocorrida entre 1999 e 2011. Nos primeiros anos deste período, associada à recuperação da economia brasileira, houve a valorização do salário-mínimo, a geração de empregos formais e a difusão do Programa Bolsa Família (PBF), por meio do qual ocorre a transferência direta de renda para as famílias mais pobres, resultando na elevação de sua renda per capita. Conforme demonstra o autor, nesse período o incremento da renda dos $20 \%$ das famílias do estrato mais baixo foi maior que o dos 10\% das famílias de maior renda, sendo este um dos fatores que contribuiu para a redução da desigualdade. Contudo, embora a geração de postos de trabalho formais tenha aumentado, "a taxa de desemprego das famílias em extrema pobreza cresceu” (DEDECCA, 2010, p. 184), e observou-se redução da renda proveniente do trabalho na renda total das famílias beneficiárias do Programa Bolsa Família. 
Embora indicadores de renda, consumo, condições de vida e acesso à educação tenham apresentado redução no período analisado, o patamar de desigualdade ainda é muito elevado no país, requerendo, segundo a avaliação de Dedecca (2014, p. 472), "esforço em termos de crescimento e mobilização da política pública", a fim de alcançar melhores níveis, mais próximos daqueles encontrados nos países desenvolvidos.

\section{AS CAUSAS E A SUPERAÇÃO DA DESIGUALDADE E DA POBREZA}

As diferenças entre os indivíduos de uma mesma sociedade - sexo, etnia, idade, profissão etc. - são inerentes ao mundo humano e fazem parte da diversidade. Barros (2005) esclarece que elas são da ordem das essências e não podem ser evitadas com a ação humana; portanto, sempre existirão. Essas diferenças, contudo, podem ser tratadas com igualdade ou com desigualdade, concedendo privilégios ou restrições a um ou a outro indivíduo, independentemente de serem iguais ou não. "O contraste entre igualdade e desigualdade refere-se quase sempre não a um aspecto 'essencial', mas a uma 'circunstância' associada a uma forma de tratamento" (BARROS, 2005, p. 345, grifos do autor).

$\mathrm{O}$ autor argumenta que entre igualdade e diferença coloca-se uma oposição por "contrariedade", que é do âmbito das essências. Já a oposição entre igualdade e desigualdade é do âmbito das "contradições", que são sempre circunstanciais. "As contradições são geradas no interior de um processo, tem uma história, aparecem num determinado momento ou situação [...]” (BARROS, 2005, p. 346). As desigualdades, por serem circunstanciais, são reversíveis, ou seja, ocorrendo mudanças de estado podem ser reduzidas ou eliminadas. Assim, conforme o autor, a diferença entre os indivíduos é um aspecto a ser considerado, enquanto a desigualdade é um aspecto a ser superado. 
As três grandes esferas da desigualdade que predominam nas relações sociais são a riqueza, o poder e o prestígio. Para Barros (2005, p. 349), a desigualdade relativa à riqueza admite tanto reversibilidade como gradações entre seus extremos. No Brasil, as desigualdades relativas à riqueza tornam-se assunto de fundamental relevância devido à enorme discrepância existente entre o estrato mais rico e o mais pobre da população, e pela presença marcante da face mais perversa desta desigualdade: a pobreza e as condições sub-humanas em que vivem muitas famílias do estrato de menor renda.

O documento Pobreza e Desigualdade no Brasil (UNESCO, 2003, p. 18) aponta que "a América Latina é a região mais desigual do mundo, sendo que $5 \%$ da população de maior renda detém $25 \%$ do PIB e $30 \%$ da população de menor renda só possui 7,6\%". Os aspectos mais cruéis da desigualdade são a pobreza e a exclusão social, cuja pauperização submete um grande contingente de pessoas a viver em condições de grande precariedade, tornando-se um grave problema para toda a sociedade.

A fim de compreender as causas das desigualdades, o posicionamento de Narloch (2015) demonstra que algumas características tipicamente brasileiras, das quais nos orgulhamos, contribuem para a concentração de renda e aumento da desigualdade. Uma delas é o livre mercado, a liberdade, da qual ninguém quer abrir mão e que, no entanto, gera concentração de renda. Segundo o autor, quando um grande contingente de pessoas escolhe comprar um bem ou contratar um serviço em detrimento de outro está contribuindo para a concentração de renda, pois o serviço ou bem escolhido acumulará mais renda, gerando desigualdade. Isto é, o livre mercado cria desigualdades, não porque os capitalistas são exploradores ou opressores, mas porque cada um tem liberdade para escolher como gastar o próprio dinheiro.

Outro fator que explica a desigualdade no Brasil é a sua enorme diversidade, uma mistura de inúmeros povos e culturas em um território muito vasto. São exemplos disso os povos indígenas que vivem na Amazônia e que não possuem renda formal e os imigrantes europeus donos de 
grandes empresas. (NARLOCH, 2015). Grupos tão diversos, num mesmo território, elevam os índices de desigualdade. Entre esses dois extremos, o autor destaca que doze das quinze cidades mais igualitárias do Brasil são gaúchas, de origem alemã. O que torna a desigualdade muito pequena nessas cidades é a semelhança entre os cidadãos, já que quase todos têm a mesma cultura e o mesmo nível de educação. Narloch (2015) entende que não são as políticas públicas ou a taxação sobre as fortunas que promoveram a igualdade nessas cidades, mas principalmente a homogeneidade da população. Assim como as maiores desigualdades são encontradas principalmente nas grandes cidades, onde se reúnem grupos populacionais muito diferentes entre si.

O nível educacional foi ressaltado por Narloch (2015) como um potente fator de desigualdade, pois quanto maior a escolarização e a qualificação, maiores são as oportunidades de emprego e maior é a remuneração. No que se refere ao aspecto educação como componente importante da desigualdade, Pizzio (2008) faz menção às correntes teóricas que atribuem a desigualdade às diferenças de acesso às oportunidades para o desenvolvimento das capacidades de cada indivíduo. Nesse sentido, a igualdade de condições é uma "estratégia de combate às desigualdades socialmente produzidas" (PIZZIO, 2008, p. 81) e mais especificamente o acesso à educação, pois a diferença de anos de estudo reflete diretamente na desigualdade de renda. "Cerca de $28 \%$ das pessoas que possuem 15 anos ou mais de estudo auferem rendimentos superiores a 10 salários-mínimos. Já na parcela que possui entre 11 e 14 anos de estudo, somente 3,8\% atingem essa faixa de rendimento, com 10 anos ou menos de estudo, o percentual assume valores abaixo de 1\%" (PIZZIO, 2008, p. 82). Portanto, mais anos de estudo significa possibilidade de remuneração mais elevada.

Outro aspecto, entre os vários componentes que contribuem para o aumento das desigualdades de renda no Brasil, refere-se aos salários, às aposentadorias e pensões dos funcionários públicos. Medeiros e Souza (2013, p. 19) realizaram estudo para medir a contribuição do gasto público para a 
desigualdade de renda no Brasil. Os autores mencionam que "a remuneração do funcionalismo e a Previdência Social são [...] as duas maiores fontes de fluxos estatais". Os salários dos funcionários públicos contribuem para o aumento da desigualdade, pois, em geral, o teto está acima dos salários pagos pelo setor privado. E as aposentadorias e pensões do funcionalismo público são provenientes de Regimes Próprios de Previdência Social (RPPS), que possuem regras diferenciadas do regime do setor privado, o Regime Geral da Previdência Social (RGPS). Enquanto o RGPS possui um piso e um teto salarial, tanto para a contribuição quanto para o pagamento dos benefícios, o RPPS tem um piso, mas paga aposentadorias e pensões que excedem esse teto, sendo, portanto, um fator promotor de desigualdade. Segundo Medeiros e Souza (2013, p. 19), “estas duas fontes de rendimento - diferencial salarial e previdenciário - transferem valores elevados para clientelas muito diminutas". No entendimento dos autores, o "Estado contribui para uma grande proporção da desigualdade no Brasil. Cerca de um terço da desigualdade total pode ser diretamente relacionada às transferências e aos pagamentos feitos pelo Estado aos indivíduos e às famílias" (p. 21). A constatação dos autores é de que a contribuição do Estado para a desigualdade é bem maior que a contribuição do setor privado, pois o mercado de trabalho privado responde por mais de $60 \%$ da renda disponível, enquanto os salários e benefícios dos funcionários públicos são muito mais concentrados.

Analisando os efeitos da Previdência Social para a contribuição da desigualdade, Medeiros e Souza (2013, p. 24) entendem que:

A desagregação entre as aposentadorias e pensões dos setores público e privado, contudo, confirma o alto grau de heterogeneidade do sistema. Na prática, o Sistema Previdenciário brasileiro está estratificado em pelo menos três grupos. No nível mais baixo, há uma massa de aposentadorias e pensões iguais ao salário-mínimo, altamente subsidiadas e pagas a antigos trabalhadores rurais ou urbanos que viveram mais ou menos à margem do mercado de trabalho formal. No meio, há os aposentados do setor privado e a 
parcela dos servidores públicos inativos cujos benefícios são menores ou iguais ao teto legal do RGPS. No topo, há alguns poucos funcionários públicos cujas aposentadorias e pensões excedem - e muito, em alguns casos - o teto do RGPS. O grupo dos funcionários públicos cujas aposentadorias e pensões excedem o teto representa menos de $5 \%$ dos beneficiários, mas se apropria de quase $20 \%$ dos recursos distribuídos pela Previdência.

Detalhando o papel do Estado na amplificação das desigualdades, os autores argumentam que as vagas de trabalho do setor público destinam-se a profissionais mais instruídos e mais qualificados que a média dos trabalhadores em geral, sendo também melhores remunerados. Nesse quadro têm grande contribuição a força e o poder de barganha dos sindicatos que representam esses trabalhadores, que conseguem negociar aumentos salariais e concessão de benefícios maiores que os do setor privado. Os servidores públicos constituem categorias ocupacionais numerosas e com um único empregador, o que contribui para a constituição de sindicatos bem organizados, atuantes e com forte poder de barganha.

No seu estudo, Medeiros e Souza (2013) constatam também que nem todas as transferências monetárias do Estado são concentradoras de renda. Os programas da Assistência Social focalizados na diminuição da pobreza efetivamente contribuem para a redução das desigualdades, mas seu impacto é muito limitado, uma vez que representam apenas $1 \%$ da renda líquida nacional. Para os autores, "os tão celebrados pilares do sistema brasileiro de combate à pobreza - o Programa Bolsa Família e o Benefício de Prestação Continuada - funcionam muito bem, mas são apenas uma gota de redistribuição em meio a um mar de ações estatais regressivas" (p. 26). Eles concluem que:

[...] o resultado final é um sistema de proteção social altamente estratificado. Em um extremo, uma grande quantidade de famílias pobres só pode contar com os parcos recursos distribuídos pela Assistência Social ou, no máximo, com benefícios equiparados ao salário-mínimo para os idosos ou portadores de deficiência. 
No outro extremo, uns números reduzidos de servidores públicos muito bem pagos durante sua vida ativa desfrutam ainda de um sistema previdenciário mais (MEDEIROS, SOUZA, 2013, p. 27).

Vendo o problema sob outra perspectiva, Dedecca (2014) afirma que a redução das desigualdades no Brasil está estreitamente relacionada ao crescimento econômico e às características que ele assume. Nos anos de 2001 a 2004, a recuperação da economia brasileira aumentou os níveis de rendimento do trabalho nos diversos estratos, decorrente da política de valorização do salário-mínimo e da geração de novos empregos formais. Ao mesmo tempo, o governo federal implantou o Programa Bolsa Família, realizando transferência de renda para as famílias em situação de pobreza e extrema pobreza. Essa política pública, associada ao aumento da oferta de emprego, promoveu o aumento da renda corrente das famílias mais pobres.

$\mathrm{O}$ autor aponta o crescimento econômico, a geração de empregos formais, a inflação baixa, a balança comercial superavitária e as políticas públicas de transferência de renda como fatores favoráveis à redução das desigualdades e elevação dos níveis de renda dos diversos estratos da população que ocorreram em um ambiente macroeconômico estável. Ainda segundo o autor, "a continuidade do movimento de redução da desigualdade depende do bom desempenho da economia e da sua capacidade em dinamizar o mercado" (DEDECCA, 2014, p. 475), o que traz como consequência direta o aumento da oferta de emprego e indiretamente amplia a capacidade do governo de financiar as políticas sociais. Outro fator apontado pelo autor, importante no movimento de redução das desigualdades e que favoreceu a preservação do poder de compra das famílias do estrato mais baixo, na década de 2000, foi a dinâmica da inflação, que nesse período se manteve no patamar de um dígito.

Quanto às políticas públicas e aos programas de transferência de renda, Dedecca (2014) atribui grande importância a essas iniciativas governamentais, destacando a difusão do Programa Bolsa Família como responsável 
pela elevação da renda corrente das famílias mais pobres. Asserburg e Gaiger (2007), no entanto, afirmam que o êxito desses programas depende de ações que possibilitem aos beneficiários a atuação como agentes na recuperação da sua dignidade, que se encontra fragilizada devido à exposição sistemática à carência, ao desemprego e à instabilidade de renda. Atrelada a tais programas, deve-se criar oportunidade de vivência de experiências positivas de participação, reconhecimento e desenvolvimento de capacidades que possibilitem a geração de renda por conta própria e, assim, a superação por si mesma da situação de pobreza e melhoria de suas condições de vida.

Outro autor que trata sobre a redução das desigualdades é Mercadante (2003), que, como Dedecca, menciona o crescimento econômico e o controle inflacionário como importantes para alcançar este escopo, mas acrescenta que não são suficientes para alterar os determinantes da pobreza e da desigualdade, sendo necessária a realização de mudanças estruturais. Entre as mudanças necessárias, ele cita o fortalecimento da democracia, engajando a sociedade na discussão sobre as políticas públicas e na participação da vida pública, quebrando a "lógica patrimonialista e autoritária do Estado brasileiro" (MERCADANTE, 2003, p. 46). A segunda estratégia, segundo o autor, é tratar o problema da inclusão social como prioridade, desenvolvendo ações visando: promover melhores condições de vida a um grande contingente de cidadãos brasileiros que "sobrevivem em condições de extrema precariedade, sem acesso aos bens e serviços essenciais a uma vida minimamente digna" (p. 47); promover o acesso e proteção ao trabalho formal; e a universalização dos serviços e direitos sociais. A terceira ação é o fortalecimento do mercado interno, tornando-o capaz de incorporar os excluídos e transformá-los em produtores, consumidores e cidadãos.

Entre as políticas que podem acelerar a construção de um modelo econômico mais igualitário, Mercadante (2003) menciona: a recuperação do salário-mínimo; a incorporação no sistema previdenciário dos trabalhadores do setor informal; a reforma agrária; a reforma urbana, ampliando 
o acesso da população de baixa renda à propriedade imobiliária; e a educação. No quesito educação, o autor afirma que:

\begin{abstract}
[...] as deficiências quantitativas e qualitativas do sistema educacional constituem um dos principais problemas estruturais do país e um dos fatores que favorecem a concentração de renda e contribuem para a perpetuação das fortes desigualdades que caracterizam a sociedade brasileira (MERCADANTE, 2003, p. 50).
\end{abstract}

Mercadante (2003), assim como Dedecca (2014), acentua que o modelo econômico concentrador e excludente é um dos principais fatores promotores de desigualdade, porém acrescenta que há outros agravantes como o "caráter regressivo do sistema tributário e a apropriação privada dos recursos públicos pelos grupos que controlam ou se beneficiam do poder político" (p. 39). Enquanto Dedecca atribui quase exclusivamente ao modelo econômico capitalista a causa das enormes desigualdades em nosso país, Mercadante, Narloch, Medeiros e Souza acrescentam em suas análises outros fatores que, segundo eles, são mais determinantes na concentração de renda e aumento da desigualdade. Assim também as ações para redução da desigualdade, que para Dedecca (2014) se concentram na retomada do crescimento econômico, para Mercadante (2003) abrangem um leque maior de ações governamentais.

No mesmo viés de Mercadante, Asseburg e Gaiger (2007, p. 505) argumentam que o crescimento econômico por si mesmo não gera redução das desigualdades e nivelamentos de renda, afirmando que "a desigualdade não é funcional ao desenvolvimento econômico e tampouco um traço inerente à modernização", sendo a pobreza e a desigualdade inclusive desfavoráveis ao crescimento econômico. A fim de produzir efeitos significativos na redução das desigualdades são necessários outros meios, não apenas políticas macroeconômicas. Os autores indicam que o crescimento econômico não é um empecilho à redução das desigualdades, mas por si só não produz distribuição de renda e redução da pobreza. 
Como meio para promover a desconcentração de renda, Asseburg e Gaiger (2007, p. 507) indicam a necessidade de adotar medidas de ativação econômica dos setores menos favorecidos, promovendo "o protagonismo dos pobres como requisito para que as políticas em seu favor sejam sustentáveis e duráveis", com incentivos para pequenas unidades produtivas formar uma base produtiva dinâmica capaz de gerar novos postos de trabalho, promovendo a inclusão no mercado produtivo. As experiências de economia solidária são uma iniciativa capaz de propiciar esse protagonismo, através da reunião de pessoas por meio de práticas participativas, de cooperação e autogestão. Os empreendimentos solidários de geração de renda têm por princípio o fortalecimento da capacidade de ação das camadas mais pobres e "eliminam a divisão entre trabalhadores e meios de produção, e entre produção e apropriação dos frutos do trabalho" (ASSEBURG; GAIGER, 2007, p. 509), presentes na lógica de produção capitalista.

No sentido de encontrar estratégias eficazes para a redução da desigualdade, Medeiros (2003), em vez de realizar estudo sobre a pobreza, põe-se a estudar o outro extremo da desigualdade, os ricos, por ser uma elite que tem grande poder de influência nas decisões do Estado e, por isso, forte impacto sobre o destino das massas da população. $\mathrm{O}$ autor constata que o crescimento da economia, nos níveis em que vem ocorrendo nas últimas décadas, mesmo havendo razoável distribuição entre a população, não é suficiente para reduzir expressivamente a pobreza. Análises realizadas pelo autor o levaram a concluir que:

[...] a afirmação de que a sociedade brasileira é extremamente desigual deve ser mais bem qualificada. O que realmente ocorre é que a população brasileira é segmentada entre uma grande massa relativamente homogênea em torno da pobreza e uma pequena, porém muito rica elite (MEDEIROS, 2003, p. 31).

Nesse cenário, a estratégia de redução da desigualdade que produziria efeitos significativos e imediatos seria a adoção de medidas redistributivas 
de renda, "transferindo recursos dos mais ricos aos mais pobres, pelo menos até o nível necessário para que a pobreza seja erradicada" (MEDEIROS, p. 35).

Olhando a questão da pobreza e da desigualdade sob o prisma do indivíduo ao invés do prisma estrutural ou conjuntural, reportamos a entrevista de Antonio Meneghetti ${ }^{1}$ concedida à revista Performance Líder. O entrevistado, ao analisar as dificuldades individuais para a superação da pobreza, explicita que a discrepância entre ricos e pobres:

[...] depende de uma psicologia arraigada na infância, através da educação, que depois resulta em uma espécie de 'preguiça'; o sujeito assume uma postura de 'parasitar' o afeto, o acolhimento. [...] Substancialmente, não se desenvolve nele uma reação a se tornar, a se qualificar, a amadurecer, a se aperfeiçoar, portanto, a colher os instrumentos de aprendizagem, de saber, de ofícios no trabalho. Em outras palavras ele não aprendeu a selecionar as oportunidades que podem ajudá-lo a ser autônomo em sentido econômico, e a base da liberdade é a autonomia econômica (MENEGHETTI, 2010, p. 50).

Essa atitude de "parasita" é decorrente do tipo de educação tida na infância. Não tanto a educação do sistema formal, mas a educação dada pela família, pela sociedade, pelo sistema que, com sua cultura excessivamente assistencialista, favorece esse parasitismo, justificando e valorizando a pobreza. Considerando que a cultura sistêmica promove essa atitude, Meneghetti refere que a própria sociedade, o próprio sistema deve:

[...] começar a ensinar a responsabilidade, o sentido de dever, sobretudo em relação a si mesmo e, por consequência, também em relação aos outros, [...] É preciso começar uma indireta pedagogia

1 Antonio Meneghetti, eminente cientista e analista social, reconhecido e respeitado pela ONU, consultor do ECOSOC e conferencista da UNESCO, foi presidente da Associação Internacional de Ontopsicologia, ONG com status Consultivo Especial junto ao Conselho Econômico e Social (ECOSOC) das Nações Unidas. Em 2000 realiza um simpósio internacional junto a UNESCO. Realização de conferência na Conference Room 1do Palácio de Vidro das Nações Unidas em 5 de janeiro de 2001. Em setembro de 2003 participou do painel "Governance and public administration" promovido pelo United Nations Department of Economic and Social Affairs (UNDESA). Realização de conferência na UNESCO com o tema "Uma nova pedagogia para a sociedade futura", em 30 de maio de 2006. 
cultural, sem condenar. Temos que ajudar, pois cada um de nós também é o outro, e quando vejo um homem pobre, um homem doente, sinto-me tocado na minha humanidade e procuro auxiliar, procuro dar ao outro a minha cultura, a minha inteligência, se ele o permite (MENEGHETTI, 2010a, p. 51).

$\mathrm{O}$ autor entende que, "além do enorme assistencialismo operado por todos os governos do mundo, a ideologia de uma democracia tem dado gratuitamente um direito que, ao invés disso, deve ser merecido pelas pessoas” (MENEGHETTI, 2004, p. 93). Segundo ele, todos têm potencialmente os mesmos direitos, "mas antes de termos os benefícios, é preciso saber demonstrá-los historicamente" (p. 93).

De acordo com esse posicionamento, parte-se do pressuposto de que todo ser humano possui intrínseca a capacidade de superação das dificuldades com as quais se depara e tem potencialmente a possibilidade de autorrealização, segundo a medida de cada um. É certo que o ambiente social no qual o indivíduo nasce e se desenvolve lhe impõe limites, mas é igualmente certo que não inviabiliza o crescimento e a evolução da pessoa. Por mais adverso que seja o ambiente, o ser humano é dotado de capacidades que lhe permitem superar tais dificuldades. Uma semente jogada em terra fértil, com abundância de água se desenvolve frondosa e exuberante; se colocada em solo árido, rochoso, será menos vistosa, mas não perde seu potencial e, de algum modo, ele se manifesta e produz frutos. É um princípio da natureza, e negar esse princípio é considerar que alguns são melhores que os outros. É considerar que alguns não são capazes de manter-se por si próprios, por isso precisam ser mantidos pelo Estado, pela sociedade.

Em geral, as medidas apresentadas para a superação da pobreza são medidas assistencialistas, pois entendem que o Estado deve prover os meios para suprir as necessidades dos indivíduos em situação de pobreza. Sobre o assistencialismo, no entendimento de Meneghetti, trata-se de uma: 
[...] forma de preferência em relação a todos aqueles que são subdesenvolvidos, persiste como modelo de dar de comer sem ensinar como ganhar a comida, com isso se gratifica o infantilismo das massas. Hoje é suficiente ser pobre para ter o direito da garantia de muitas leis. [...] Com isso perdemos a dialética do mérito, a dinâmica do capaz. O pior disso tudo é o fato de gratificar o infantilismo do homem. Tal contexto de preferências em relação ao deficiente é um subverter os valores fundamentais da vida. Sustento que insistir no assistencialismo é um assassínio ideológico, moral e psicológico. Quanto mais me prostituo para ajudar o deficitário em vez de provocá-lo e ensiná-lo como se cresce, mais sou artífice da sua inferioridade (MENEGHETTI, 2004, p. 94, grifo do autor).

O autor avalia que esse assistencialismo é "uma mentalidade que destrói o orgulho, a ambição e a necessidade ao primado de todos aqueles aos quais impomos a ajuda. Ajudar significa humilhar e dar exaltação gratuita a quem se considera superior: é uma ofensa ao orgulho primário da inteligência do homem" (MENEGHETTI, 2004, p. 231). Para ele, trata-se de uma "forma de piedade que desonra a dignidade humana" (p. 96).

Em outra passagem, Meneghetti (2004, p. 210) é ainda mais firme quando afirma ter feito outra análise, na qual notou que todos os assistidos, "além de se tornarem estúpidos e necessitados, são sempre progressivamente mais pobres". Os assistidos, segundo o autor, "tomam o dinheiro com irresponsabilidade, o consomem em pequenos vícios e pequenas curiosidades, e se tornam cada vez mais estúpidos e necessitados" (p. 210).

Uma vez que vivemos em sociedade, ela tem o dever de propiciar condições ao pleno desenvolvimento de seus indivíduos, o que se torna um direito deles. Mas o indivíduo também tem deveres com essa sociedade. Por exemplo, o dever de empenhar-se no desenvolvimento de si mesmo, através do estudo e aprimoramento de habilidades que preparam para o cumprimento de outro dever primordial, o autossustento. A provisão, a ajuda, sem a responsabilização, é uma forma perversa de manter o outro dependente e inferiorizado. Sobre os deveres, Meneghetti (2004, p. 49) 
orienta que "além de compartilhar nossas riquezas, façamos com que aquele pobre compartilhe também dos nossos deveres de educação e de estudo. Se devemos dar o nosso bem-estar, é justo que paguem e respeitem as nossas leis de introdução no social". Quanto ao aspecto da ajuda, May (1988, p. 17, p. 20) esclarece que "o processo de ajudar outras pessoas pode na verdade torná-las conformistas e tender à destruição da individualidade”. O autor chama a atenção para o fato de que o indivíduo possui potencialidades e características únicas, que são reprimidas e, por isso, deixam de ser vivenciadas pela pessoa. A repressão das potencialidades "levanta a questão da margem de liberdade do ser humano com respeito a suas potencialidades, uma margem onde reside a responsabilidade sobre si mesmo". Os dois autores, além do compromisso da sociedade com a promoção do bem-estar dos seus indivíduos, ressaltam as capacidades e responsabilidade individual na construção desse bem-estar. Mas o aspecto mais importante abordado pelos autores é a liberdade do indivíduo, aliada à vontade. Sair da pobreza, garantir o autossustento é uma escolha e empenho pessoal; é a possibilidade de tornar-se autônomo e independente economicamente. A dependência das políticas do Estado torna o indivíduo subserviente, submisso e massa de manipulação deste mesmo Estado.

\section{CONSIDERAÇÕES FINAIS}

A problemática das desigualdades e da pobreza é muito mais uma problemática do indivíduo do que decorrência de um modelo econômico. Com isso, não se pretende afirmar que o indivíduo se encontra em dificuldade exclusivamente porque não se esforçou o bastante. Entende-se que o pouco empenho é decorrente de um modelo cultural que valoriza e gratifica excessivamente a pobreza e, com isso, está matando o potencial humano, como refere Meneghetti (2004, p. 94): “está matando 
a verdadeira alma do homem prometeico que potencialmente existe em cada homem".

Como medida de superação da pobreza, muitos teóricos apontam as medidas distributivas de renda, de riqueza, como uma das ações a serem adotadas pelos governos. Quem produz a riqueza a ser distribuída é o sistema produtivo, o mercado, os capitalistas. Mas, afinal, quem é o sistema produtivo? São pessoas que se empenham ao máximo para ter melhores condições de vida, primeiro para si e, por consequência, também para os outros. O empreendedor ou o capitalista como pejorativamente denominam alguns, no entendimento de Meneghetti (2004, p. 95), "é o homem capaz de realizar o próprio potencial em função individual e em função do coletivo próximo. É um homem que alcança o mais gratificante para si mesmo através do útil para os outros". É o operador que assume responsabilidades, corre riscos para abrir, manter e ampliar seu negócio, gerando centenas ou até milhares de empregos que possibilitam trabalho e renda para muitos. É o setor produtivo que não só proporciona possibilidade de trabalho, como também gera a riqueza, sem a qual não se poderia falar em medidas distributivas.

As medidas de combate à pobreza e redução da desigualdade de cunho assistencialista, como as políticas de redistribuição de renda, desconsideram esse potencial individual. Parece que consideram o indivíduo incapaz e o colocam numa situação de impotência. Se o Estado e a sociedade não proveem os meios de superação das condições sub-humanas de vida, o indivíduo está fadado a permanecer nessa situação. Em tempos idos, a riqueza era considerada uma graça divina; agora, é uma graça do Estado. No entanto, a crítica a essas medidas não significa dizer que se deve abandonar os menos favorecidos à própria sorte. Uma vez que é o próprio sistema, com a sua cultura social que incrementa a pobreza, é, sim, responsabilidade do sistema, dos governos e da sociedade adotar medidas para superá-la. Todavia, as medidas devem ser no sentido de uma nova pedagogia, como aponta Meneghetti (2004), ensinando 
como se ganha a própria comida, estimulando o autodesenvolvimento. Ou como refere Pizzio (2008), facilitando o acesso às possibilidades de aprimoramento das capacidades individuais. Ou, ainda, como apontam Asseburg e Gaiger, oportunizando a vivência de experiências de desenvolvimento de capacidades que promovam a geração de renda e superação da situação de pobreza por si próprio. Com isso devolve-se a dignidade, o orgulho e a confiança em si mesmo, em vez de ficar esperando pela providência do Estado.

Empreender significa "determinar-se a realizar uma tarefa, realizar uma mudança de caráter voluntário, cujo resultado é primordialmente um ganho individual, [...] é uma jornada em busca do novo, uma vida construída pelas próprias capacidades" (CALDEIRA, 2009, p. 169). Temos inúmeros exemplos de homens que nasceram muito pobres e, com empenho e determinação, superaram essa situação inicial, alguns construindo grandes fortunas, outros com discreta economia que lhes garante viver com dignidade. Os pequenos e grandes exemplos são demonstrações de empreendedorismo e revelam que o ser humano não tem necessidade de assistencialismo ou de garantia de direitos, mas tem necessidade de apoio, incentivo e facilitações para investir o seu potencial. Essa é a mola do crescimento e do desenvolvimento econômico e social.

Em última instância, pode-se dizer que a situação de pobreza, de carência é decorrente da estruturação do sistema socioeconômico, mas no fim é o indivíduo que deve decidir e empenhar-se com vontade, como fazem os mais abastados, cabendo ao sistema a adoção de medidas que propiciem o fortalecimento da capacidade de ação dos indivíduos mais pobres, favorecendo-se a melhoria das suas condições de vida e o desenvolvimento social como um todo. 


\section{REFERÊNCIAS}

ASSEBURG, H. B.; e GAIGER, L. I. A Economia Solidária diante das Desigualdades. Revista de Ciências Sociais, 2007: p. 499-533.

CALDEIRA, J. História do Brasil com empreendedores. São Paulo: Mameluco, 2009.

DEDECCA, C. S. A redução da desigualdade e seus desafios. In: CALIXTRE, A. B.; BIANCARELLI, A. M.; CINTRA, M. A. M. (Ed.). Presente e futuro do desenvolvimento brasileiro. Brasília: IPEA, 2014. p. 469-511.

MAY, R. A descoberta do ser. Rio de Janeiro: Rocco, 1988.

MEDEIROS, M. O que faz os Ricos ricos: um estudo sobre fatores que determinam a riqueza.Tese de Doutoramento, Brasília, 2003.

MEDEIROS, M.; SOUZA, P. Gasto público, tributos e desigualdade de renda no Brasil. Texto para discussão. Brasília: IPEA, 2013.

MENEGHETTI, A. As raízes da pobreza.Entrevista concedida à Revista Performance Líder. São Paulo: Ontopsicologica, jun. 2010.

. Sistema e personalidade. Recanto Maestro: Ontopsicologica Editrice, 2004.

MERCADANTE, A. Construindo estratégias para combater a desigualdade social: uma perspectiva socieconômica. In: WERTHEIN, J; NOLETO, M. J. Pobreza e desigualdade no Brasil. Brasília: UNESCO, 2003. p. 37-51.

NARLOCH, L. Guia politicamente incorreto da economia brasileira. São Paulo: Leya, 2015.

PIZZIO, A. As políticas sociais de reconhecimento como elemento de redução das desigualdades sociais. Revista Ciências Sociais, São Leopoldo, v. 44, p. 80-86, 2008. 